\title{
A Tale of Two Ectopics: Two Cases Depicting the End Spectra of Ectopia Lentis
}

\author{
Abhishek 0* \\ Associate Consultant, Centre for Sight Jodhpur, India \\ *Corresponding author: Abhishek Onkar, Associate Consultant, Centre for Sight \\ Jodhpur, India, Email: onkaratdmch@gmail.com
}

\section{Case Report}

Volume 2 Issue 3

Received Date: September 30, 2017

Published Date: November 03, 2017

\section{Abstract}

Aim: To bring in perspective the two extremes of dysmorphic syndrome presenting with ectopia lentis.

Methods and Material: A nine year old female with history of bilateral gradual painless diminution of vision and a twelve year old female with similar complaints underwent a thorough systemic, ophthalmic and serological examination.

Results: Increased corneal diameters and bilateral supero-temporally displaced pupils with infero-nasally displaced lens were detected with normal systemic features and serology in the first patient who was subsequently diagnosed as a case of ectopia lentis et pupillae (ELeP). Temporally displaced lens with normally placed pupil was observed in the second patient who was subsequently diagnosed as a case of Marfan's syndrome. Systemic evaluation revealed aortic root dilatation, mitral valve prolapse and arachnodactyly.

Conclusions: While the patient with ELeP had no systemic abnormalities and its management required only spectacle correction, Marfan's syndrome patient had grave systemic abnormalities requiring a multi-speciality approach to its management. This paper highlights the two extremes of dysmorhic syndrome having ectopia lentis at presentation, with ELeP at one end of spectrum without any systemic involvement and Marfan's syndrome at the grave end of the spectrum with plethora of dire systemic abnormalities.

Keywords: Ectopia Lentis; Prolapsed; Arachnodactyly; Marfan's Syndrome; Dysmorphic

\section{Introduction}

Ectopialentis is defined as displacement or mal position of the crystalline lens of the eye. It was first described by Berryat in 1749 while the term was coined by Stellwag in 1856. Though trauma remains the most common cause of ectopia lentis, a multitude of congenital anomalies are associated with it [1]. The congenital diseases can have ectopia lentis as the presenting feature, enabling their early identification and management during routine screening ophthalmic examination of children. While most of these syndromes like Marfan's syndrome have grave systemic abnormalities, some can have ectopia lentis as the sole feature. This makes the early and precise diagnosis of these entities essential so as to treat the systemic abnormalities and prolong longevity on one hand and provide visual rehabilitation to reduce morbidity and enhance holistic growth of the child on the other hand [2] (Table 1). 


\section{Open Access Journal of Ophthalmology}

\begin{tabular}{|c|c|}
\hline Congenital zonular weakness & Secondary ectopia lentis \\
\hline A. No systemic involvement: & A. Traumatic: \\
\hline i. Isolated ectopialentis & \\
\hline ii. Ectopialentis et pupillae & B. Others: \\
\hline B. Systemic involvement: & i. High myopia \\
\hline i. Marfan's syndrome (cardiac evaluation) & ii. Chronic uveitis \\
\hline ii. Homocystinuria (serum/urine homocysteine/methionine levels) & iii. Anirridia \\
\hline iii. Weil-Marchesiani syndrome (brachydactyly, short stature) & iv. Buphthalmos \\
\hline iv. Sulphite oxidase deficiency (urinary thiosulfate, urine sulfite dipstick & \\
\hline v. Hyperlysinaemia & \\
\hline
\end{tabular}

Table 1: Differential diagnosis of ectopia lentis with suggested work-up.

\section{Case Reports}

A twelve year old female with history of bilateral gradual painless diminution of vision and a nine year old female with similar complaints underwent a thorough systemic, ophthalmic and serological examination.

Temporally displaced lens with normally placed pupil was observed in the first patient who was subsequently diagnosed as a case of Marfan's syndrome. Systemic evaluation revealed aortic root dilatation, mitral valve prolapse and arachnodactyly with positive wrist (Walker) and thumb (Steinberg) signs. Increased corneal diameters and bilateral supero-temporally displaced pupils with infero-nasally displaced lens were detected with normal systemic features and serology in the second patient who was subsequently diagnosed as a case of ectopial entis et pupillae (ELeP).

\section{Case summary of patient-1}

Complaints and history: twelve year old female, presented with complaint of painless, gradual diminution of vision in both eyes for 1 year

\begin{tabular}{|c|c|c|}
\hline & Right eye (OD) & Left eye(OS) \\
\hline Uncorrected Visual acuity(VA-Snellen's) VA with pin-hole & $\begin{array}{l}5 / 60 \\
6 / 18\end{array}$ & $6 / 60$ \\
\hline Near Visual acuity & $\mathrm{N}-6$ & $\mathrm{~N}-6$ \\
\hline Best corrected visual acuity(BCVA) & $-7.50 \mathrm{DS},-1.25 \mathrm{DC}, 20 *-6 / 18$ & -7.0DS, $-1.5 \mathrm{DC}, 160 *-6 / 12$ \\
\hline Intra*ocular pressure(IOP Schiotz) & $17.3 \mathrm{~mm}$ of $\mathrm{Hg}$ & 17.3 \\
\hline Iris & Normal colour and pattern & Normal colour and pattern \\
\hline Lens & $\begin{array}{l}\text { SUBLUXATED SUPERO- } \\
\text { TEMPORALLY with extended } \\
\text { zonules }\end{array}$ & $\begin{array}{l}\text { SUBLUXATED SUPERO- } \\
\text { TENPORALLY }\end{array}$ \\
\hline Systemic examination & \multicolumn{2}{|c|}{$\begin{array}{l}\text { Aortic root dilatation } \\
\text { Positive wrist sign(Walker) } \\
\text { gn(Steinberg)Increased am span (ARM SPAN } \\
\text { Arachnodactyly pectus craniatum present }\end{array}$} \\
\hline $\begin{array}{c}\text { Serological } \\
\text { examination }\end{array}$ & \multicolumn{2}{|c|}{ Iron deficiency anemia } \\
\hline
\end{tabular}

Table 2: Case summary of patient-1 


\section{Open Access Journal of Ophthalmology}

\begin{tabular}{|c|c|c|}
\hline \multicolumn{3}{|c|}{ Case summary of patient-2 } \\
\hline \multicolumn{3}{|c|}{$\begin{array}{c}\text { Complaints and history: nine year old female, presented with complaint of painless, gradual diminution of vision in } \\
\text { both eyes for three months }\end{array}$} \\
\hline & Right eye(OD) & \begin{tabular}{c|c} 
& Left eye(OS) \\
\end{tabular} \\
\hline $\begin{array}{l}\text { Un-corrected Visual acuity(VA- } \\
\text { Snellen's)VA with pin-hole }\end{array}$ & $\begin{array}{c}6 / 18 \\
6 / 9\end{array}$ & $\begin{array}{l}6 / 18 \\
6 / 9\end{array}$ \\
\hline Near VA & $\mathrm{N}-6$ & $\mathrm{~N}-6$ \\
\hline $\begin{array}{l}\text { Best Corrected Visual } \\
\text { Acuity(BCVA) }\end{array}$ & $-9.0 \mathrm{DS},-2.0 \mathrm{DC}, 140 *-6 / 9$ & $-9.0 \mathrm{DS},-2.0 \mathrm{DC}, 40 *-6 / 9$ \\
\hline Intra-ocular pressure (IOP-NCT) & $18 \mathrm{~mm}$ of $\mathrm{Hg}$ & $18 \mathrm{~mm}$ of $\mathrm{Hg}$ \\
\hline Cornea & $\begin{array}{c}\text { Corneal diameters increased } \\
\text { Horizontal: } 13 \mathrm{~mm} \text { vertical: } 14 \mathrm{~mm}\end{array}$ & $\begin{array}{l}\text { Corneal diameters increased H: } 13 \mathrm{~mm} \\
\text { V: } 14 \mathrm{~mm}\end{array}$ \\
\hline Iris & IRIDODONESIS & IRIDODONESIS \\
\hline Pupil & $\begin{array}{l}\text { Slightly oval Displaced towrads } 11 \text { 'o } \\
\text { clock position Slightly sluggish reacting }\end{array}$ & $\begin{array}{l}\text { Slightly oval Displaced towrads 1'o } \\
\text { clock position Slightly sluggish reacting }\end{array}$ \\
\hline Lens & $\begin{array}{l}\text { SUBLUXATED inferonasally } 4 \text { clock } \\
\text { hours, with broken zonules superiorly }\end{array}$ & $\begin{array}{l}\text { SUBLUXATED inferonasally } 4 \text { clock } \\
\text { hours, with broken zonules superiorly }\end{array}$ \\
\hline Systemic examination & No abnorm & lly detected \\
\hline Serological examination & Parameters witl & in normal limits \\
\hline
\end{tabular}

Table 3: Case summary of patient-2

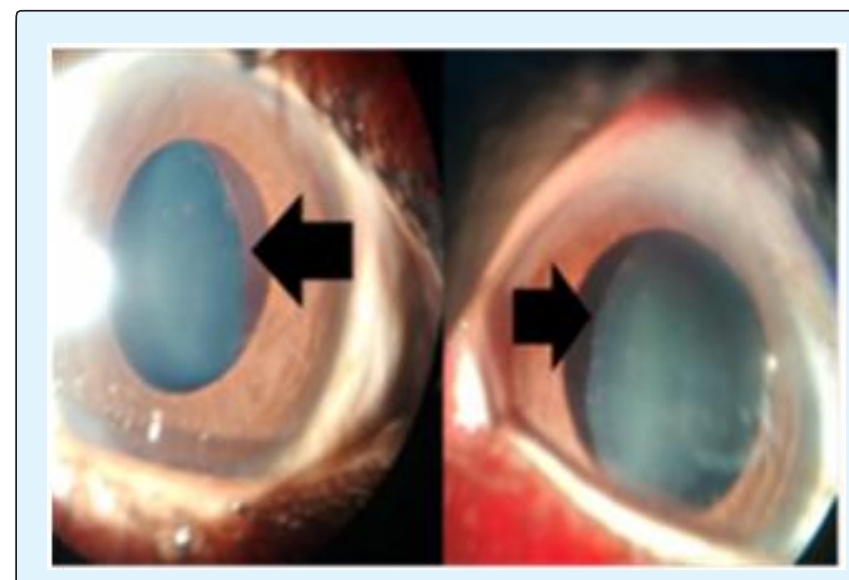

Figure 1: temporal subluxation of lens.

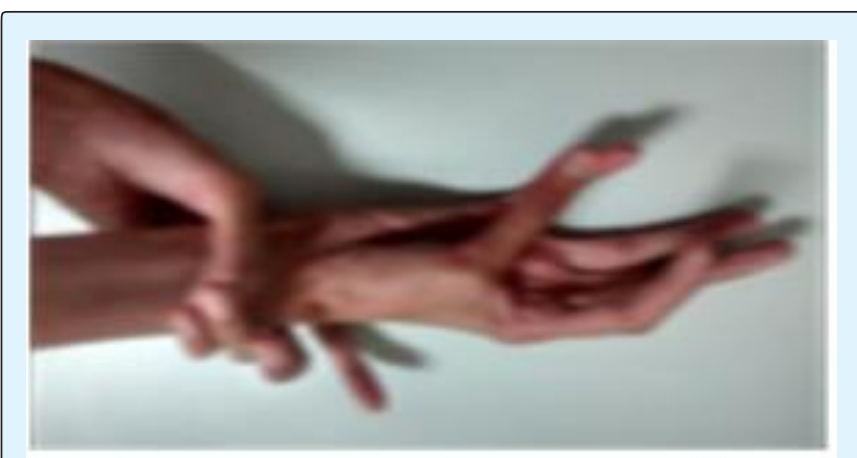

Figure 2: Positive Wrist (Walker) sign.
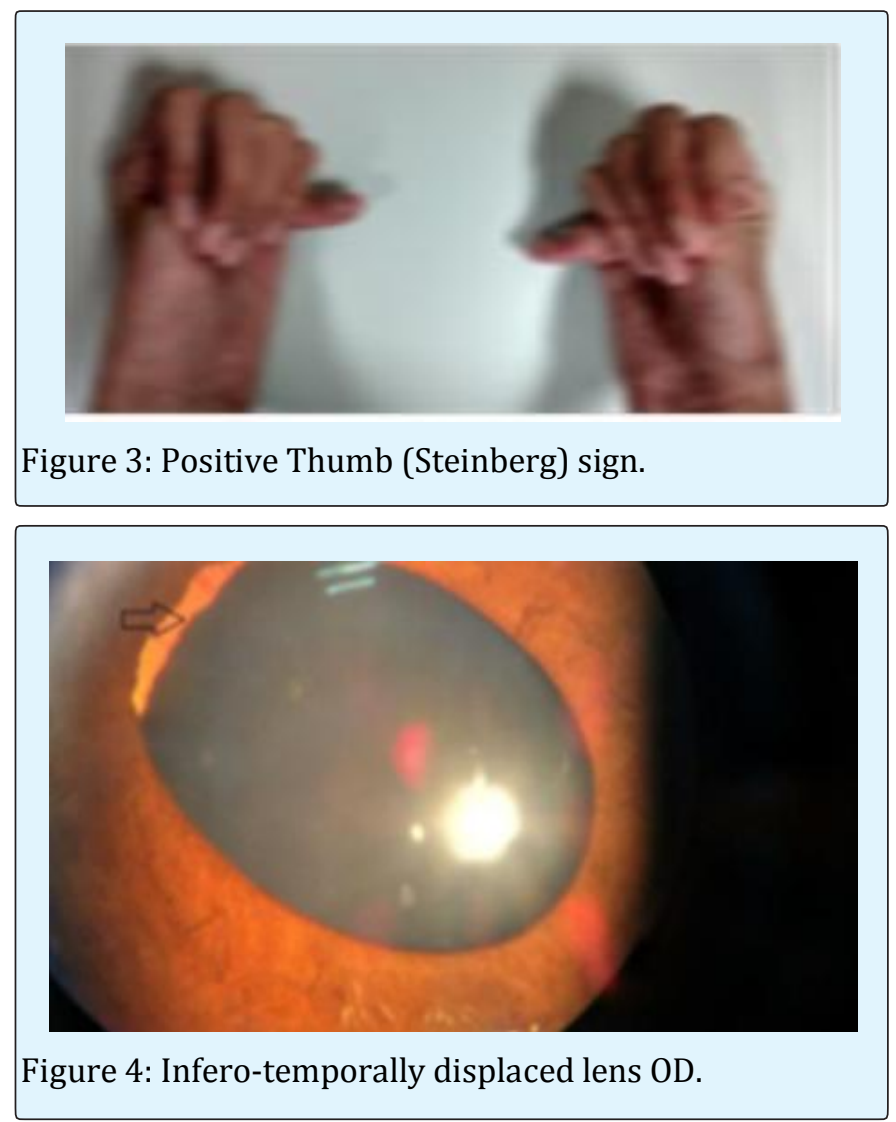

Figure 4: Infero-temporally displaced lens OD. 


\section{Open Access Journal of Ophthalmology}

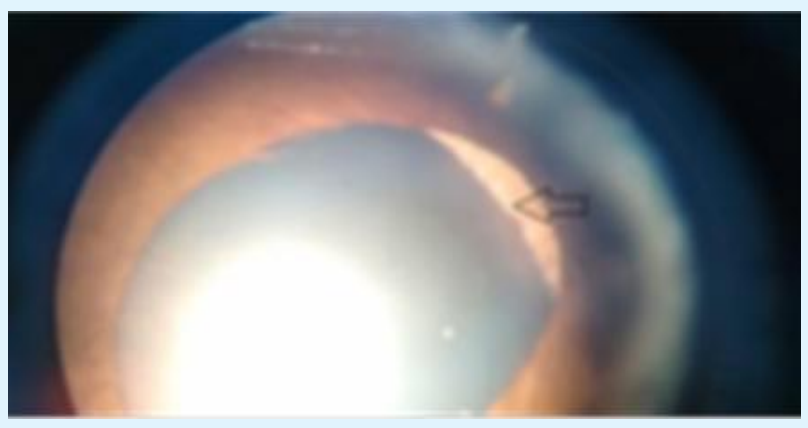

Figure 5: Infero-temporally displaced lens OS.

The first case (Marfan's syndrome) was started on tablet Ramipril 25mg OD, tablet Revolol 50mg OD with extensive physiotherapy and joint stretching exercises. She was advised regular follow-up for cardiac monitoring. The second case (Ectopia lentis et pupillae) was devoid of any systemic involvement and required only visual rehabilitation. Visual rehabilitation by means of spectacle correction was resorted to with good acceptance by the patient in both cases. On follow-up visits, parents reported substantial academic improvement and satisfaction on part of the child.

\section{Discussion}

Marfan's syndrome is the most common cause of ectopia lentis while ectopia lentis et pupillae is amongst the rarest. These two cases encompass the entire gamut of dysmorphic syndromes with ectopia lentis as the diagnostic aid in both.

Studies by Matsuo et al. and Shafique, et al. have advocated childhood ophthalmic screening for early detection and rehabilitation of these RASopathies with lens involvement. In our study, initial diagnosis of both these conditions was made incidentally during ophthalmological examination, leading to visual comfort in both the patients and detection and management of lethal cardiovascular abnormalities in the case with Marfan's syndrome $[3,4]$.

\section{Conclusion}

While the patient with ELeP had no systemic abnormalities and its management required only spectacle correction, Marfan's syndrome patient had grave systemic abnormalities requiring a multi-speciality approach to its management. This paper highlights the two extremes of dimorphic syndrome having ectopia lentis at presentation, with ELeP at one end of spectrum without any systemic involvement and Marfan's syndrome at the grave end of the spectrum with plethora of dire systemic abnormalities.

\section{References}

1. Nelson LB, Maumenee IH (1982) Ectopia lentis. Surv Ophthalmol 27(3): 143-160.

2. Fuchs J, Rosenberg T (1998) Congenital ectopia lentis. A Danish national survey. Acta Ophthalmol Scand 76(1): 20-26.

3. Matsuo T (2015) How far is observation allowed in patients with ectopia lentis?. Springer Plus 4: 461.

4. Shafique M, Muzaffar W, Ishaq M (2016) The eye as a window to a rare disease: ectopia lentis and homocystinuria, a Pakistani perspective. Int Ophthalmol 36(1): 79-83. 